\title{
EVALUASI STRUKTUR KOLOM KUAT BALOK LEMAH STRUKTUR RANGKA BAJA MENGACU SNI 1729-2015 (STUDI KASUS : GEDUNG SCIENCE TECHNO PARK - ITB)
}

\author{
Muhamad Ryanto, ST., M.T \\ Fakultas Teknik, Jurusan Teknik Sipil, Universitas Sangga Buana YPKP
}

\begin{abstract}
ABSTRAK
Struktur Gedung Perkuliahan ITB Bandung yang terdiri dari 4 lantai dievaluasi terhadap Sistem Rangka Pemikul Momen Khusus (SRPMK) dengan mengacu pada SNI baja yang berlaku (SNI 1726-2015/RSNI 1729-201x), Struktur rangka baja dievaluasi dengan mengaplikasikan konsep desain kapasitas (capacity design concept). Kajian ini menganalis sambungan balok agar terjadinya sendi plastis sesuai dengan konsep struktur kolom kuat balok lemah (strong columm weak beam). Dalam kajian analisis ini, diperhitungkan bahwa kapasitas kolom dan balok dengan memperhitungkan kapasitas lentur dua arah dengan pertimbangan desain gaya pada kolom dikalikan pembesaran nilai faktor keamanan, sehingga efek pembesaran momen yang terjadi sudah diperhitungkan terhadap kelangsingan penampang sehingga desain tersebut memenuhi kriteria konsep kolom kuat balok lemah.

Hasil analisis menunjukkan bahwa besaran nilai gaya momen lentur kolom nominal lebih besar dari momen lentur gaya luar sehingga sendi plastis terjadi dibagian sambungan balok dan kolom. Untuk tinjauan kasus ini, kolom masih dalam kondisi aman..
\end{abstract}

Kata kunci: capacity design, strong column weak beam, sendi plastis

\section{PENDAHULUAN}

\section{Latar Belakang}

Konstruksi bangunan bertingkat semakin banyak dibangun akibat dari semakin kurangnya ketersediaan lahan. Dalam mendesain bangunan gedung bertingkat peran struktur kolom sangat vital terhadap dari kekuatan suatu struktur bangunan. Struktur kolom merupakan bagian dari sistem struktur portal/frame dan berfungsi sebagai elemen pengaku struktur dengan dihubungkan elemen balok, dan memikul distribusi beban dari titik-titik sambungan balok-kolom, sedangkan balok elemen struktur yang memikul dan mendistribusikan beban-beban dari balok dan lantai.

Dalam desain struktur dibuat kondisi dimana balok harus mengalami kondisi perlemahan yaitu dengan terjadinya sendi-sendi plastis, sehingga kerusakan bangunan tidak membuat bangunan menjadi runtuh, dan struktur kolom harus didesain kuat terhadap gaya lateral gempa dan masih mampu menopang kerusakan struktur akibat kerusakan yang hanya tejadi pada kerusakan balok pada sambungan balok dan kolom.

Dengan kondisi keruntuhan bangunan di atas maka diperlukan desain struktur dengan konsep Kolom Kuat Balok Lemah (Strong Column Weak Beam) sehingga jika pada suatu saat terjadi gempa besar, kolom struktur harus didesain kuat dan balok boleh terjadi kerusakan berupa sendi plastis pada sambungan, sehingga manusia yang berada di dalam bangunan gedung masih mempunyai 
waktu untuk menyelamatkan diri sebelum jika nantinya bangunan akan runtuh total.

\section{Perumusan Masalah}

Penelitian ini akan mengevaluasi analisis perencanaan struktur bangunan dengan menerapkan metode Desain Kapasitas

Ultimit (Ultimate Capacity Design) dan menggunakan sistem konsep struktur kolom kuat balok lemah sehingga memberikan kepastian keamanan pada struktur bangunan ini.

Berdasarkan hasil evaluasi desain, maka dapat diambil rumusan masalah yaitu:

1. Apakah Gedung Science Techno Park ITB yang sudah ada sekarang sudah memenuhi konsep kolom kuat balok lemah ?

2. Letak titik runtuh pada sendi plastis balok harus didesain sebaik mungkin, dimana titik sendi plastis tersebut diharapkan terjadi di balok dengan cara meningkatkan kekuatan unsur yang berbatasan pada kolom.

\section{Batasan Masalah}

Permasalahan dibatasi sebagai berikut:

1. Menggunakan metode desain kapasitas ultimit

2. Desain struktur kolom dan balok menggunakan profil baja IWF

3. Evaluasi kinerja desain sambungan balok dan kolom pada struktur rangka baja.

4. Melakukan analisis sambungan struktur berdasarkan kondisi struktur dengan Sistem Rangka Baja Pemikul Momen

\author{
Khusus (SRPMK) yang dituangkan \\ dalam RSNI 1729-201x.
}

\section{Tujuan dan Manfaat Penelitian}

Tujuan penelitian ini adalah:

- Mengevaluasi kinerja struktur serta merencanakan sambungan balok-kolom pada sebuah bangunan dengan cara desain kapasitas ultimit sehingga sistem sambungan struktur memenuhi konsep kolom kuat balok lemah.

- Menghasilkan pengetahuan desain terhadap sambungan balok-kolom tentang perlakuan sendi plastis balok terhadap kolom.

\section{METODOLOGI PENELITIAN}

Analisis kolom kuat balok lemah digunakan untuk mengetahui kondisi kinerja struktur bangunan akibat beban gempa. Dimana analisis yang dilakukan secara mengacu pada SNI 1729.1-2015, RSNI 1729.2-201x dan SNI 1729.3-2013.

\section{LANDASAN TEORI}

\section{Desain Kapasitas}

Dalam perencanaan struktur, perencanaan limit states design-nya disebut Ultimate Capacity Design atau Desain Kapasitas Ultimit yang berarti bahwa ragam keruntuhan struktur akibat pembebanan dengan memperhitungan faktor pembesaran beban pada sehingga terjadi kondisi elemenelemen balok kritis dengan mekanisme 
keruntuhannya struktur saat kondisi keruntuhan ultimit.

Agar elemen-elemen balok dapat terjadi kondisi plastis dengan secara sempurna maka elemen-elemen sambunga balok lainnya harus direncanakan agar keruntuhan sendi plastis terjadi di bagian sambungan, untuk itu harus didesainkan bahwa elemen kolom pada pertemuan titik sambungan dengan balok harus lebih kuat dibandingkan sambungan elemen-elemen balok. Sehingga memenuhi kriteria kondisi yang dikenal dalam perencanaan capacity design disebut Kolom Kuat Balok Lemah (Strong Column Weak Beam).

\section{Sambungan Balok - Kolom}

Sistem sambungan struktur rangka baja ini mempunyai kriteria sebagai berikut :

- Analisis desain struktut dengan SRPMK direncanakan mampu mengalami deformasi plastis akibat gempa rencana, melalui kelelahan sendi plastis balok pada rangkanya dan kelelehan pada ujung kolom dasar.

- Kolom didesain lebih kuat daripada balok yang leleh dan mencapai strainhardening.

- Desain sambungan balok ke kolom harus didasarkan pada hasil uji sambungan.

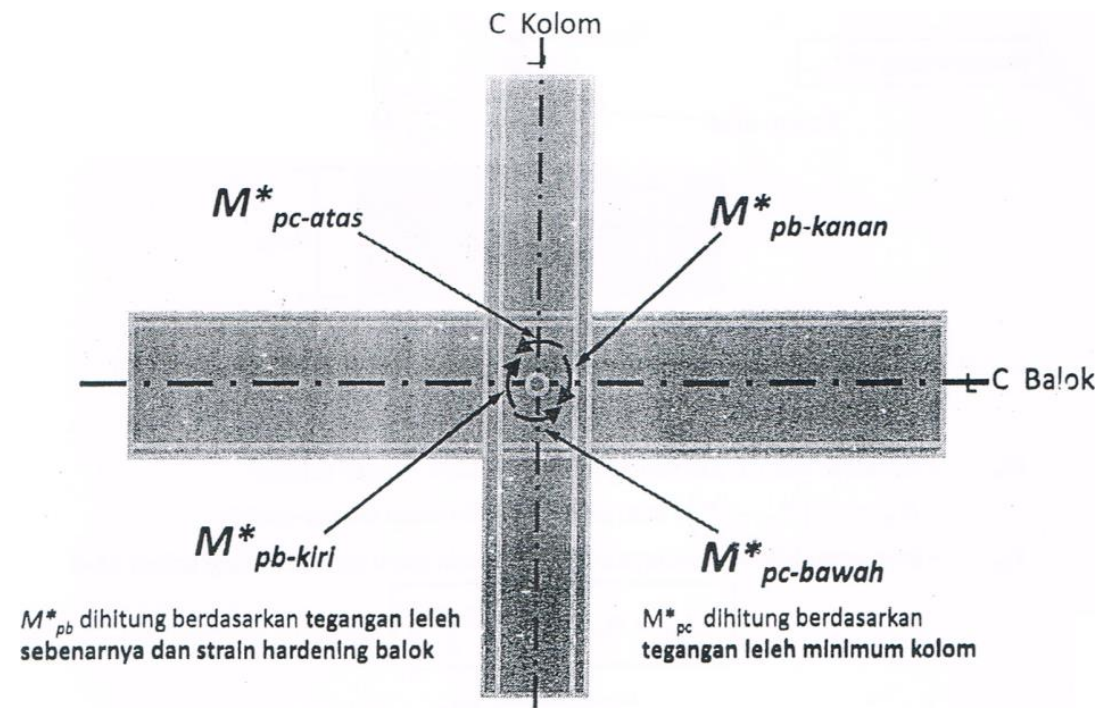

Gambar 1. Hubungan Kolom dan Balok

Perhitungan kriteria sambungan kolom kuat balok lemah ditentukan sebagai berikut :

$$
\frac{\sum M_{p c}^{*}}{\sum M_{p b}^{*}}>1.0
$$

Dimana :

$$
\begin{aligned}
\Sigma M_{p c}^{*}= & \text { jumlah momen pada kolom } \\
& \text { bawah dan atas di bagian } \\
& \text { sambungan pada pertemuan } \\
& \text { antara sumbu kolom dan balok } \\
& \text { dan dihitung berdasarkan } \\
& \text { penjumlahkan proyeksi kuat } \\
& \text { lentur nominal kolom, di atas } \\
& \text { dan bawah sambungan pada }
\end{aligned}
$$


sumbu balok, dengan mereduksi akibat gaya aksial tekan kolom berdasarkan rumus sebagai berikut :

$$
\sum M_{p c}^{*}=\sum Z_{c}\left(F_{y c}-\frac{P_{u c}}{A_{g}}\right)
$$

$\Sigma M_{p b}^{*}=$ jumlah momen balok pada pertemuan antara sumbu balok dan kolom dan didesain dengan menjumlahkan proyeksi kuat lentur nominal balok, di daerah sendi plastis balok pada sumbu kolom.

Mekanisme terjadinya momen plastis pada balok seperti ditunjukkan pada Gambar 2 :

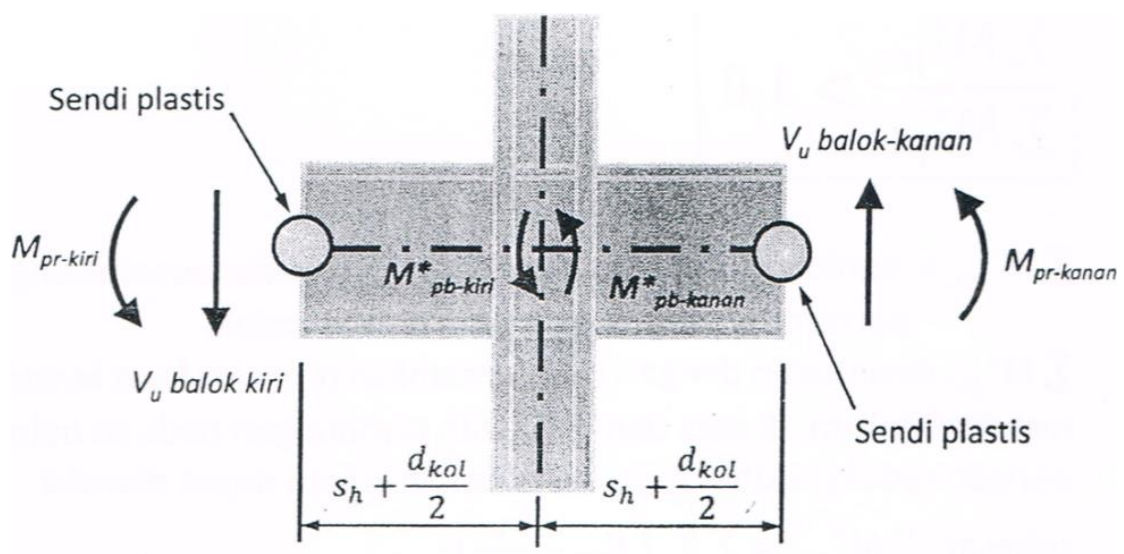

Gambar 2. Mekanisme Momen Plastis pada Balok

Perhitungan momen plastis pada balok :

$$
M_{p b}^{*}=M_{p r}+V_{\text {beam }}\left(S_{h}+\frac{d_{c o l}}{2}\right)
$$

$S_{h} \quad=$ jarak mula kolom ke lokasi sendi plastis balok (sesuai AISC 358)

Dimana :

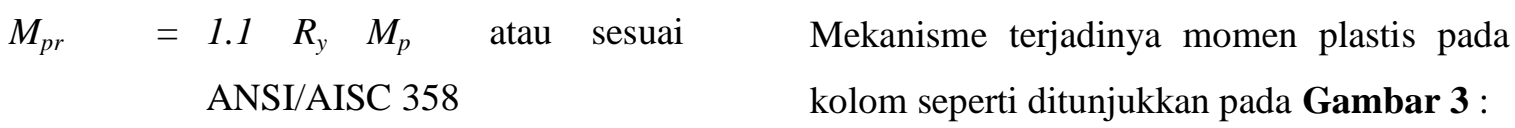

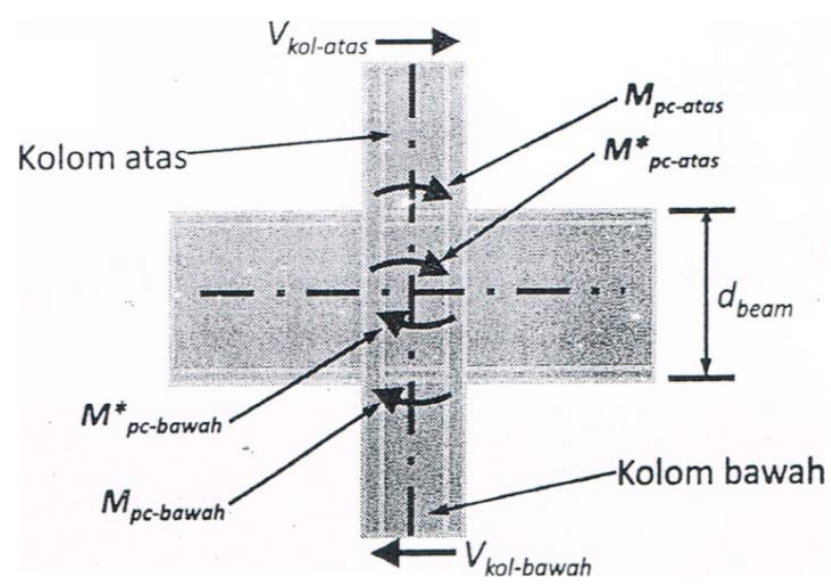

Gambar 3. Mekanisme Momen Plastis pada Kolom 
Perhitungan momen plastis pada kolom :

$$
M_{p c}^{*}=M_{p c}+V_{c o l}\left(\frac{d_{b e a m}}{2}\right)
$$

Dimana :

$$
\begin{aligned}
M_{p c}= & \text { kapasitas momen plasti nominal } \\
& \text { kolom, dapat diambil sebesar : } \\
& M_{p c}=Z_{c}\left(F_{y c}-\frac{P_{u c}}{A_{g}}\right) \\
& (\text { atau perhitungan interaksi } \\
& \text { momen aksial }) \\
V_{k o l}= & \text { gaya geser kolom, diasumsikan } \\
& \text { dihitung pada lokasi setengah } \\
& \text { tinggi kolom, } M=0
\end{aligned}
$$

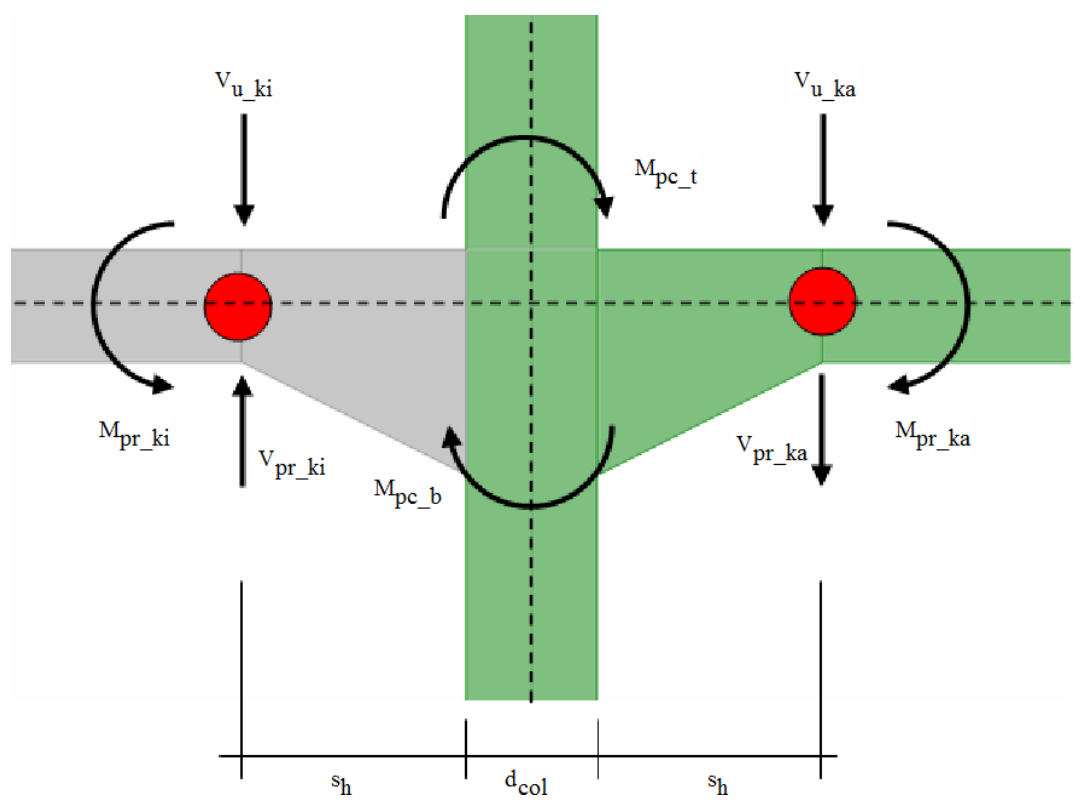

Gambar 4. Gaya-Gaya yang Bekerja pada Sambungan Kolom Balok

- Data Material :

$$
\begin{array}{ll}
\mathrm{E}:=2 \cdot 10^{5} \cdot \mathrm{MPa} & \longrightarrow \quad \text { (Modulus baja) } \\
\mathrm{F}_{\mathrm{y}}:=240 \cdot \mathrm{MPa} & \longrightarrow \quad(\text { Tegangan leleh baja) }
\end{array}
$$

- Kolom menggunakan profil baja WF350×350:

$$
\begin{aligned}
& \mathrm{Z}_{\mathrm{x}}:=2493.182 \cdot \mathrm{cm}^{3} \longrightarrow \quad \text { (Modulus penampang plastik) } \\
& \mathrm{A}_{\mathrm{g}}:=137.9 \cdot \mathrm{cm}^{2}
\end{aligned}
$$


- Gaya dalam aksial yang bekerja pada kolom

$\mathrm{P}_{\mathrm{u}}:=576 \cdot \mathrm{kN} \quad \longrightarrow \quad$ (kondisi pembebanan Ultimate)

- Menghitung Momen plastis pada kolom :

$$
\begin{aligned}
\Sigma \mathrm{M}_{\mathrm{pc}} & =2 \cdot \mathrm{Z}_{\mathrm{x}} \cdot\left(240-\frac{\mathrm{P}_{\mathrm{u}}}{\mathrm{A}_{\mathrm{g}}}\right) \\
\Sigma \mathrm{M}_{\mathrm{pc}} & :=2 \cdot \mathrm{Z}_{\mathrm{x}} \cdot\left(\mathrm{F}_{\mathrm{y}}-\frac{\mathrm{P}_{\mathrm{u}}}{\mathrm{A}_{\mathrm{g}}}\right) \\
& \Rightarrow \Sigma \mathrm{M}_{\mathrm{pc}}=988.45 \mathrm{kN} \cdot \mathrm{m}
\end{aligned}
$$

- Balok kiri menggunakan profil baja IWF300x150 :

$$
\begin{aligned}
& \mathrm{Z}_{\mathrm{X}}:=522.076 \cdot \mathrm{cm}^{3} \quad \rightarrow \quad \text { (Modulus penampang plastik) } \\
& \mathrm{R}_{\mathrm{y}}:=1.5 \\
& \mathrm{~L}:=6 \cdot \mathrm{m} \quad \longrightarrow \quad \text { (bentang balok) } \\
& \mathrm{s}_{\mathrm{h}}:=600 \cdot \mathrm{mm} \quad \longrightarrow \quad \text { (Jarak dari muka kolom ke sendi plastis) } \\
& \mathrm{d}_{\mathrm{c}}:=350 \cdot \mathrm{mm} \quad \longrightarrow \quad \text { (lebar kolom) } \\
& \mathrm{L}_{\mathrm{h}}:=\mathrm{L}-\mathrm{d}_{\mathrm{c}}-2 \cdot \mathrm{s}_{\mathrm{h}} \quad \longrightarrow \quad \text { (Jarak antara dua sendi-plastis) } \\
& \Rightarrow \quad \mathrm{L}_{\mathrm{h}}=4.45 \mathrm{~m} \\
& \mathrm{~V}_{\mathrm{u} \_\mathrm{ki}}:=124.1 \cdot \mathrm{kN} \quad \longrightarrow \quad \text { (kondisi pembebanan Ultimate) }
\end{aligned}
$$

- Menghitung Momen plastis pada balok :

$$
\begin{aligned}
& \mathrm{M}_{\text {pr_ki }}=1.1 \cdot \mathrm{R}_{\mathrm{y}} \cdot \mathrm{F}_{\mathrm{y}} \cdot \mathrm{Z}_{\mathrm{x}} \\
& \mathrm{M}_{\text {pr_ki }}:=1.1 \cdot \mathrm{R}_{\mathrm{y}} \cdot \mathrm{F}_{\mathrm{y}} \cdot \mathrm{Z}_{\mathrm{x}} \quad \Rightarrow \quad \mathrm{M}_{\mathrm{pr} \_\mathrm{ki}}=206.742 \mathrm{kN} \cdot \mathrm{m}
\end{aligned}
$$

- Menghitung gaya geser akibat momen plastis :

$$
\mathrm{V}_{\text {pr_ki }}:=2 \cdot \frac{\mathrm{M}_{\text {pr_ki }}}{\mathrm{L}_{\mathrm{h}}} \quad \Rightarrow \quad \mathrm{V}_{\text {pr_ki }}=92.92 \mathrm{kN}
$$


- Balok kanan menggunkan profil baja IWF300x150 :

$\mathrm{Z}_{\mathrm{X}}:=522.076 \cdot \mathrm{cm}^{3} \quad \longrightarrow \quad$ (Modulus penampang plastik)

$\mathrm{R}_{\mathrm{y}}:=1.5$

$\mathrm{L}:=6 \cdot \mathrm{m}$

$\longrightarrow$ (bentang balok)

$\mathrm{s}_{\mathrm{h}}:=600 \cdot \mathrm{mm}$

$\longrightarrow$ (Jarak dari muka kolom ke sendi plastis)

$\mathrm{d}_{\mathrm{c}}:=350 \cdot \mathrm{mm}$

$\longrightarrow \quad$ (lebar kolom)

$$
\begin{aligned}
\mathrm{L}_{\mathrm{h}} & :=\mathrm{L}-\mathrm{d}_{\mathrm{c}}-2 \cdot \mathrm{s}_{\mathrm{h}} \quad \longrightarrow \quad \text { (Jarak antara dua sendi-plastis) } \\
& \Rightarrow \quad \mathrm{L}_{\mathrm{h}}=4.45 \mathrm{~m}
\end{aligned}
$$

$\mathrm{V}_{\mathrm{u} \_\mathrm{ka}}:=96.6 \cdot \mathrm{kN} \quad \longrightarrow \quad$ (kondisi pembebanan Ultimate)

- Menghitung Momen plastis pada balok :

$$
\begin{aligned}
& \mathrm{M}_{\mathrm{pr} \text { ka }}=1.1 \cdot \mathrm{R}_{\mathrm{y}} \cdot \mathrm{F}_{\mathrm{y}} \cdot \mathrm{Z}_{\mathrm{x}} \\
& \mathrm{M}_{\mathrm{pr} \text { ka }}:=1.1 \cdot \mathrm{R}_{\mathrm{y}} \cdot \mathrm{F}_{\mathrm{y}} \cdot \mathrm{Z}_{\mathrm{x}} \quad \Rightarrow \quad \mathrm{M}_{\mathrm{pr} \_\mathrm{ka}}=206.742 \mathrm{kN} \cdot \mathrm{m}
\end{aligned}
$$

- Menghitung gaya geser akibat momen plastis :

$$
\mathrm{V}_{\text {pr_ka }}:=2 \cdot \frac{\mathrm{M}_{\text {pr_ki }}}{\mathrm{L}_{\mathrm{h}}} \quad \Rightarrow \quad \mathrm{v}_{\text {pr_ka }}=92.92 \mathrm{kN}
$$

- Pertemuan Balok - Kolom :

$$
\begin{aligned}
& \mathrm{M}_{\mathrm{v}}:=\left[\left(\mathrm{v}_{\mathrm{pr} \_\mathrm{ki}}-\mathrm{v}_{\mathrm{u}_{-} \mathrm{ki}}\right)+\left(\mathrm{v}_{\mathrm{pr} \_\mathrm{ka}}+\mathrm{v}_{\mathrm{u}_{-} \mathrm{ka}}\right)\right] \cdot\left(\mathrm{s}_{\mathrm{h}}+\frac{\mathrm{d}_{\mathrm{c}}}{2}\right) \\
& \mathrm{M}_{\mathrm{v}}=122.71 \mathrm{kN} \cdot \mathrm{m} \\
& \Sigma \mathrm{M}_{\mathrm{pb}}:=\mathrm{M}_{\mathrm{pr} \_\mathrm{ki}}+\mathrm{M}_{\mathrm{pr} \_\mathrm{ka}}+\mathrm{M}_{\mathrm{v}} \\
& \Rightarrow \Sigma \mathrm{M}_{\mathrm{pb}}=536.194 \mathrm{kN} \cdot \mathrm{m}
\end{aligned}
$$

- Penentuan Kolom - Strong Column Weak Beam :

$$
\begin{aligned}
& \Sigma \mathrm{M}_{\mathrm{pc}}= 988.45 \mathrm{kN} \cdot \mathrm{m} \\
& \Sigma \mathrm{M}_{\mathrm{pb}}= 536.194 \mathrm{kN} \cdot \mathrm{m} \\
& \text { Ratio }:=\frac{\Sigma \mathrm{M}_{\mathrm{pc}}}{\Sigma \mathrm{M}_{\mathrm{pb}}} \Rightarrow \text { Ratio }=1.843 \\
& \mathrm{Cek}:=\mid \begin{array}{ll}
\text { "OK" } & \text { if Ratio }>1 \\
\text { "N.G" } & \text { otherwise }
\end{array} \\
& \mathrm{Cek}=\text { "OK" }
\end{aligned}
$$




\section{KESIMPULAN}

Berdasarkan hasil evaluasi pada struktur yang dijadikan tinjauan, diperoleh kesimpulan sebagai berikut :

1. Secara struktural, komponen sambungan struktur balok dan kolom pada bangunan ini memenuhi rancangan desain dengan menggunakan Sistem Rangka Pemikul Momen Khusus (SRPMK) yang disyaratkan RSNI 1729-201x sehingga desain tersebut memenuhi kriteria sistem struktur kolom kuat dan sendi plastis terjadi pada sambungan balok-kolom.

2. Kapasitas kekuatan lentur kolom dan balok memenuhi syarat kekuatan struktur dengan Sistem Rangka Baja Pemikul Momen Khusus dimana analisis lentur kolom pada momen lentur lebih besar daripada kuat lentur minimum kolom pada SRPMK dan peninjauan terhadap faktor-faktor pembesaran momen yang terjadi sudah dilakukan, maka struktur bangunan tersebut sudah didesain tahan terhadap gaya gempa.

\section{SARAN}

1. Dalam menganalisis atau desain penampang sebaiknya momen yang diperhitungkan akan memberikan kapasitas atau daya pikul penampang yang lebih besar sehingga lebih stabil.

2. Dalam analisis kekuatan hubungan dimana pembagian momen balok ke kolom, digunakan analisis dengan menggunakan analisis kapasitas penampang yang terpasang sehingga analisis sambungan tersebut dipastikan mengacu kepada desain struktur strong column weak beam.

\section{DAFTAR PUSTAKA}

Badan Standarisasi Nasional. Tata Cara Perencanaan Ketahanan Gempa untuk Struktur Bangunan Gedung dan non Gedung (SNI 1726-2012).

Badan Standarisasi Nasional. Spesifikasi Untuk Bangunan Gedung Baja Struktural (SNI 1729.1-2015).

Badan Standarisasi Nasional. Spesifikasi Ketentuan Desain Tahan Gempa Untuk Struktur Gedung Baja (RSNI 1729.2201x).

Badan Standarisasi Nasional. Sambungan Prakualifikasi Untuk Rangka Momen Baja Khusus Dan Menengah Untuk Aplikasi Seismik (SNI 1729.3-2013).

Budiono, B. 2011. Konsep SNI Gempa 1726:201x.Seminar HAKI

HAKI, 2012. Struktur Bangunan Baja Tahan Gempa, ”Short Course”. Jakarta. 